\title{
Anne Ibos-Augé, Chanter et lire dans le récit médiéval. La fonction des insertions lyriques dans les cuvres narratives et didactiques d'oil aux XIII et XIV siècles
}

\section{Maria Colombo Timelli}

\section{CpenEdition}

Journals

\section{Édition électronique}

URL : http://journals.openedition.org/studifrancesi/2057

DOI : 10.4000/studifrancesi.2057

ISSN : 2421-5856

Éditeur

Rosenberg \& Sellier

\section{Édition imprimée}

Date de publication : 1 avril 2014

Pagination : 116

ISSN : 0039-2944

\section{Référence électronique}

Maria Colombo Timelli, « Anne Ibos-Augé, Chanter et lire dans le récit médiéval. La fonction des insertions lyriques dans les œuvres narratives et didactiques d'oil aux xIII' et xIV siècles », Studi Francesi [En ligne], 172 (LVIII | I) | 2014, mis en ligne le 01 avril 2014, consulté le 18 septembre 2020. URL : http:// journals.openedition.org/studifrancesi/2057 ; DOI : https://doi.org/10.4000/studifrancesi.2057

Ce document a été généré automatiquement le 18 septembre 2020.

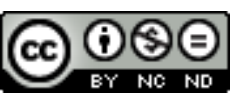

Studi Francesi è distribuita con Licenza Creative Commons Attribuzione - Non commerciale - Non opere derivate 4.0 Internazionale. 


\title{
Anne Ibos-Augé, Chanter et lire dans le récit médiéval. La fonction des insertions lyriques dans les œuvres narratives et didactiques d'oil aux XIII et XIV siècles
}

\author{
Maria Colombo Timelli
}

\section{RÉFÉRENCE}

ANNE IBOS-AUGÉ, Chanter et lire dans le récit médiéval. La fonction des insertions lyriques dans les cuvres narratives et didactiques d'oil aux XIII' et XIV siècles, Bern, Berlin, Bruxelles, Frankfurt am Main, New York, Wien, Peter Lang, 2010 («Varia Musicologica», 17), 2 volumes, pp. 1296.

1 Issu d'une thèse de doctorat soutenue en 2000 , ce gros livre constitue une synthèse interdisciplinaire entre histoire de la littérature et histoire de la musique: son objet impose en effet une double approche, littéraire et musicale, ainsi que la prise en compte de quelques aspects spécifiques à l'histoire du livre manuscrit.

2 Le corpus - qui n'est pas explicitement présenté, mais que l'on trouvera sous la forme de tables aux pp. 339-348 (Appendice I) - comprend des œuvres narratives (tant des romans que des récits brefs) et des textes à visée didactique: citons à titre d'exemple le Chastelain de Coucy et le Lai d'Aristote pour le premier groupe, le Chastoiement des dames pour le deuxième, à côté de bien d'autres pris en compte au cours de l'analyse. L'étude comprend quatre parties, auxquelles s'ajoutent des appendices et des annexes réunissant une documentation richissime.

Un premier chapitre est consacré à L'insertion comme divertissement (pp. 29-130; tableau récapitulatif en Appendice II, pp. 349-357; une section à part est réservée à Renart le 
Nouvel: Appendice III, pp. 358-368), à savoir à ces insertions dont le but premier est d'illustrer des épisodes festifs de tout genre (banquets, noces, joutes, tournois etc.). Loin de représenter «de simples enjolivements gratuits» (p. 33), les chants se révèlent en rapport étroit avec le récit conté et sont pour la plupart confiés à des personnages actifs dans la narration; la danse est alors illustrée par des rondeaux ou des rondets, et surtout par de simples refrains faisant appel aux connaissances et à la mémoire du public. Ici et dans les chapitres suivants, Anne Ibos-Augé examine la présentation des insertions lyriques dans la narration, leur justification dans le contexte (procédé qui tend à les rendre partie intégrante de la narration), leur prosodie (qui peut rompre ou au contraire s'adapter parfaitement au récit) et ses variantes éventuelles dans la tradition manuscrite. Des questions essentielles se posent au sujet de la présence d'une notation dans les manuscrits, et d'une éventuelle exécution musicale pendant la lecture des œuvres en question (les musiques sont données dans les annexes les plus importantes: pp. 473-683 pour les refrains; pp. 685-874 pour les citations longues).

4 Le deuxième chapitre concerne L'insertion comme partie intégrante du discours (pp. 131-253; tableau récapitulatif en Appendice IV, pp. 369-392; tableaux à part pour Robin et Marion, Appendice V, pp. 393-394; Renart le Nouvel, Appendice VI, pp. 395-413). Dans ces cas, l'auteur, bon connaisseur du répertoire poétique et musical, assigne la fonction de poète à un personnage, en lui attribuant la paternité des textes poétiques, qu'ils existent déjà ou qu'ils soient du cru de l'auteur même. Ici encore, auteur et lecteurs participent d'un même jeu intertextuel en partageant les mêmes connaissances poético-lyriques.

5 L'insertion comme ingérence de l'auteur ou du copiste fait l'objet du troisième chapitre, où l'on passe de la littérature narrative aux compilations de genre didactique (pp. 255-313; voir aussi les Appendices VII à X, consacrées respectivement au Ludus super Anticlaudianus, pp. 418-420; aux Miracles de Gautier de Coinci, pp. 418-420; aux insertions citées à titre d'exemple, pp. 421-430; au Rosarius, pp. 431-433). Un approfondissement est dédié au cas particulier des Miracles de la Vierge de Gautier de Coinci, dont les insertions sont examinées surtout sur le plan mélodique.

6 Le dernier chapitre s'attache à un type particulier de citations lyriques (L'insertion génératrice ou partie intégrante de la forme, pp. 315-331): il s'agit tout spécialement des textes du non-sens (rêveries, oiseuses, fatrasies), dont il est difficile de mesurer la réelle destination musicale, mais qui constituent le fondement même de l'architecture de l'œuvre qui les accueille, et des sermons appuyés sur des vers.

7 La bibliographie critique est réunie aux pp. 435-444, suivie d'un Index rerum (pp. 445-446), d'un Index nominum (pp. 447-451) et des Index des incipit (pp. 452-472).

8 Le deuxième volume - à pagination continue - comprend, comme on l'a déjà dit, deux annexes musicales et d'aussi imposantes annexes littéraires (pp. 877-1296), avec des tableaux différents en fonction de la «Situation des insertions», des «Choix métriques et prosodiques des insertions», de la prosodie par rapport au contexte. Suit encore l'édition de deux poèmes: L'abeïe dou chastel amoureus et un salut d'amour, Dame plesane et sage....

9 L'intérêt d'un tel ouvrage pour des historiens de la littérature française ne fait pas de doute, dans la mesure où il permet de mieux situer dans un panoramique large des œuvres bien connues - il suffira de rappeler des titres devenus emblématiques du genre narratif à insertions lyriques, tels Guillaume de Dole ou le Roman de la Violette - et surtout 
de traiter ces insertions dans leur double dimension, littéraire et musicale, selon une approche qui était vraisemblablement davantage celle du public médiéval. 